\title{
Pandemic-Induced Depression and Anxiety in Healthcare Professionals
}

\author{
S. WEIBELZAHL ${ }^{1}$, J. REITER ${ }^{2}$, and G. DUDEN ${ }^{3}$ \\ ${ }^{1}$ PFH Private University of Applied Sciences Göttingen, Germany \\ ${ }^{2}$ University of Vienna, Austria \& University of Lausanne, Switzerland \\ ${ }^{3}$ University of Osnabrueck, Germany \& University of Leipzig, Germany
}

\begin{abstract}
Medical staff has been at the centre of the fight against the COVID-19 pandemic, facing diverse work-related stressors. Studies from various countries have shown that healthcare professionals have an increased risk of burnout and mental disorders during pandemic outbreaks. The present study aimed to investigate what kind of workrelated stressors healthcare professionals in Germany have been facing and how they have been affected psychologically by the COVID-19 pandemic. $\mathrm{N}=300$ healthcare professionals completed an online survey including the ISR symptom checklist to measure psychological well-being and questions on help-seeking behaviour. Findings were analyzed using t-tests, regression, and comparisons to large clinical and non-clinical samples assessed before and during the pandemic. Results show that healthcare professionals were most affected by protective measures at their workplace and changes in work procedures. Psychological symptoms, especially of anxiety and depression, were significantly more severe than in a non-clinical pre-pandemic sample and in the general population during the pandemic. At the same time, most professionals indicated that they would not seek help for psychological concerns. These findings indicate that healthcare employers need to pay increasing attention to the mental health of their staff, encourage help-seeking behaviour, as well as provide access to mental health support.
\end{abstract}

Keywords: Pandemics; Occupational Stress; Mental Health; Nursing Staff; Help-Seeking Behaviour

\section{Introduction}

Globally, medical staff is at the centre of the fight against the COVID-19 pandemic. In the initial phase of the pandemic, healthcare professionals received a lot of media attention and praise from the general public for their heroic work 1]. While many employees have started working from home or have even been barred from attending their work place, employees in the healthcare sector were affected in a dual sense: not only were they required to continue working but they were exposed to increased risks due to the nature of their jobs. This twofold burden causes global economic and medical impact on the one hand, and also increases psychological strain on people on the other hand 2 .

As the pandemic spread from country to country,

Correspondence concerning this article should be addressed to Stephan Weibelzahl, PFH - Private University of Applied Sciences, Department of Psychology, Weender Landstraße 3-7, 37073 Göttingen, Germany, Tel.: +4955154700431, E-mail: weibelzahl@pfh.de studies investigated the well-being of healthcare professionals in many places, including China, Singapore, Japan, Italy, Saudi Arabia, and Switzerland 3. The well-being of this target group is of high concern as the health systems depend on their workforces and a collapse would have severe consequences for the general public.

In this study, we set out to investigate whether healthcare professionals in Germany have been affected psychologically by the COVID-19 pandemic and, if so, what kind of work-related stress they have been facing in this new situation.

\section{Evidence from Other Countries}

As China was the first country challenged by high and wide-spread infection rates of COVID-19, the first studies that explored the well-being of healthcare staff were run in Wuhan and other regions of China from January 2020 onwards [4, 5, 6, 7]. A systematic review of 14 studies on the impact on healthcare workers in different regions of China and in Singapore has demonstrated the extensive rise in experienced stress as well as depression and anxiety symptoms. Across all studies, between $2.2 \%$ 
and $14.5 \%$ of cases exhibited severe degrees of anxiety and depression symptoms. Influencing factors included age, gender, occupation, specialization, type of activities performed and proximity to COVID-19 patients 8 . Some of these findings are based on large samples. For instance, Lai et al. 9] assessed $\mathrm{N}=1257$ healthcare workers in several regions of China and found high levels of depression (50.4\%), anxiety (44.6\%), insomnia (34.0\%), and distress $(71.5 \%)$.

Increased mental health risks were also observed in Japan [10 and later on in Switzerland [3]. Italian healthcare professionals showed symptoms of burnout five weeks after the local onset of the pandemic [11. In Saudi Arabia, healthcare professionals displayed a higher level of anxiety and worries as compared to previous outbreaks of MERS-CoV in the country, despite the fact that no cases of COVID-19 were registered at the time, yet [12. Using structural equation modeling on a variety of data sources, Miller 13 demonstrated that frontline staff, who are in contact with either possible or confirmed cases of COVID-19, are exposed to even higher mental and emotional risks than other healthcare workers.

While the COVID-19 pandemic is unprecedented in regard to its extent, its rapid spread 14 and the type of protective measures applied at large scale, similar effects on healthcare staff were observed in previous outbreaks of other infectious diseases. A systematic review of 44 studies on former epidemics and pandemics showed that symptoms of mental disorders were common in healthcare workers both during and after the outbreaks 15 . Symptoms of depression were reported by $27.5-50.7 \%$, symptoms of insomnia by $34-36.1 \%$, and symptoms of severe anxiety by $45 \%$ of participants. Also, $11 \%$ and $73.4 \%$ reported post-traumatic stress symptoms. After 1-3 years, the level was still at 10-40\%.

\section{Stress Factors}

Which individual and work-related factors are considered to increase or decrease the risk of developing clinical symptoms? Many healthcare professionals worry about infecting family members, experience fears and uncertainty concerning the mortality and morbidity of the disease, and some are confronted with the death of colleagues 14, 16, 17. Surprisingly, the fear of becoming infected themselves seems to be less prominent than the fear of infecting their families 18. Intolerance of uncertainty has a strong impact on mental well-being in a pandemic setting. This is significantly mediated by rumination and fear 19 .

Key individual protective factors include social support and self-efficacy. Social support increases selfefficacy and sleep quality which in turn reduces anxiety and stress 20. It has been widely demonstrated that self-efficacy beliefs are an important moderator of the impact of work-related stressors [e.g., 21]. Self-efficacy is also one of the key concepts of the Health Belief Model 22 and a good predictor of health behaviour. Selfefficacy can reduce infection-related worries 23 and insomnia 20. However, the pandemic situation is characterized by high levels of uncertainty and rapid changes in both work and social life. A general climate of wariness and uncertainty has been observed, as there is still a lack of knowledge about the disease and no cure or vaccine is available yet. Thus, the treatment healthcare professionals can actually provide is still limited. Healthcare workers have raised concerns about not being able to provide competent care $14,7,17$. This kind of situation is detrimental for self-efficacy.

Work-related organizational factors that increase the risk for the development of clinical symptoms among healthcare professionals include depletion of personal protective equipment [16], lack of other resources such as specific drugs, ventilators and intensive care unit beds as well as communication issues such as rapidly changing information or a lack of up-to-date information 14. Changes in work practices such as having to adjust to wearing protective equipment and redeployment are also key concerns 24]. Frontline staff working with (possibly) infected patients has shown to be more affected by changes in work practices and stress than healthcare professionals who work with non-COVID-19 patients 15, 13. For detailed information on protective factors for healthcare professionals during epidemics and pandemics, see Preti et al. 15].

\section{Mental Health Support for Healthcare Professionals}

In order to improve the mental health of healthcare professionals during the COVID-19 pandemic, various intervention strategies have been proposed. For instance, healthcare providers may establish an emotional support plan, including strategies for information and screening, providing emotional support and building support networks 24]. Regular interaction among teams can help to discuss critical situations and check on mutual well-being 25 . Healthcare workers and their team leaders can also learn to apply and support selfcare strategies through e-Learning programs $[26$. In several countries telephone hotlines were established to provide immediate crisis support $27,28,29$.

However, despite the severe impact on healthcare professionals, some staff members have proven reluctant to accept mental health support. According to Chen et al. 18 professionals tend to claim not having any problems and just needing some rest without interruption.

In Germany, the pandemic took a somewhat differ- 
ent course of events than in many other countries. A strategy of early and extensive testing 30 resulted in less drastic lockdown measures than in other European countries 31] and avoided an overload of the health system.

We aimed to find out why and to what extent healthcare professionals in Germany experienced psychological distress related to the pandemic and which factors shaped their help-seeking behaviour.

\section{Method}

We created a cross-sectional online survey in order to assess healthcare professionals' mental well-being and the perceived stress factors they are experiencing.

\section{Instrument}

The first section of the survey explored participants' demographics such as age, gender and profession.

For the second section, a list of potential stress factors was compiled based on literature and informal discussions with nurses and administrative staff. Participants were asked how strongly they were affected by each stress factor using a 5-point Likert-scale from not at all to extremely. Participants could also indicate if the factor does not apply to their situation.

Psychological well-being was measured with the selfreport questionnaire ICD-10-Symptom-Rating [ISR, 32] . The ISR was originally developed to assess symptoms of psychological disorders in the German-speaking area based on the well-known ICD-10 33 including subscales for depression, anxiety, eating disorder, obsessive compulsive disorder, and somatoform disorder symptoms as well as an extra-subscale with various symptoms. It comprises a total of 29 items which are rated on a 5-point Likert-scale from 0 (does not apply) to 4 (extremely). Item ratings are averaged to compute subscale scores (three resp. four items for each disorder and 12 items for the extra subscale) as well as a total score. The ISR total score has been shown to have very good internal consistency (Cronbach's $\alpha=.92$ ). The internal consistency of the subscales is also good (Cronbach's $\alpha=.78-.86) 34$. High retest-reliability for the individual scales ranging from .70 to .94 has been reported in different clinical and non-clinical samples 35. The scale has good ability to differentiate clinical group (N $=12265, \mathrm{M}=1.22, \mathrm{SD}=0.65)$ from non-clinical control group $(\mathrm{N}=2512, \mathrm{M}=0.40, \mathrm{SD}=0.45)$, with $84 \%-88 \%$ sensitivity and $71 \%-75 \%$ specificity 36 . It also highly correlates with similar but longer instruments such as the symptom checklist SCL-90-R 37].

We chose ISR, because large clinical $(\mathrm{C}+)$ and nonclinical (C-) norm samples are available for Germany. These were assessed before the pandemic ( $\left.\mathrm{P}_{-}\right)$32, 38
Table 1

IDs and sample sizes of ISR reference groups

\begin{tabular}{rcc}
\hline & \multicolumn{2}{c}{ context } \\
\cline { 2 - 3 } & before pandemic & during pandemic \\
\hline clinical & $R_{C+P-}$ & - \\
sample & $N=12265$ & $R_{C-P+}$ \\
\hline non-clinical & $R_{C-P-}$ & $N=1744$ \\
sample & $N=2512$ & \\
\hline
\end{tabular}

and are referred to as reference groups $R_{C+P-}$ resp. $R_{C-P-}$ in our study. We also included a large sample of the general public (C-) assessed at the peak of the first wave of the pandemic $(\mathrm{P}+)$ in Germany 39$]$ which we will refer to as reference group $R_{C-P+}$ (see Table 1 ).

In the third and last section of the survey, we explored whether participants would consider different types of mental support and which barriers they experienced to seeking help for psychological strain.

\section{Sample}

Participants were recruited through healthcare providers, a press release and personal contacts between 22 May and 22 July 2020. At that time, the most severe lockdown measures to date had been lifted again across Germany, i.e., shops and restaurants were allowed to operate again and schools were slowly re-opening, but social distancing and other restrictions were still in place. No incentives were given for participation and no personally identifiable information was collected. Neither IP addresses nor GPS data were stored. All participants gave their informed consent for participation and storing responses electronically. We obtained institutional review board (IRB) approval from PFH Private University of Applied Sciences Göttingen for this procedure.

In total 300 participants completed the survey. One case had been removed previously as it was identified as a test answer. No outliers were detected. The majority of participants was female $(81 \%)$. Participants' age ranged between 17 and 65 years $(M=40.65$, $S D=12.9)$. The majority lived in Lower Saxony (59\%), North Rhine-Westphalia (9\%) and Hesse (9\%). Most of the participants were working in inpatient nursing care $(35.7 \%)$. Table 2 provides an overview of the distribution of professions among participants.

Using the statistics software $\mathrm{R}$ [Version 4.0.2; 40] in RStudio 41 and numerous helper packages, we computed basic descriptive statistics, followed by t-tests and chi-square-tests where group comparisons were war- 


\section{Table 2}

Distribution of participants' professions by gender. $N=4$ participants did not indicate their gender.

\begin{tabular}{lcccc}
\hline profession & $\mathrm{f}$ & $\mathrm{m}$ & $\mathrm{N}$ & $\mathrm{rel}$ \\
\hline inpatient nursing care & 92 & 12 & 104 & $35 \%$ \\
inpatient elder care & 23 & 5 & 28 & $9 \%$ \\
non-medical health sector & 21 & 7 & 28 & $9 \%$ \\
physical therapist & 18 & 8 & 26 & $9 \%$ \\
home care & 24 & 0 & 24 & $8 \%$ \\
social worker & 15 & 6 & 21 & $7 \%$ \\
inpatient physician & 6 & 6 & 12 & $4 \%$ \\
physician's assistant & 12 & 0 & 12 & $4 \%$ \\
psycho therapist & 7 & 1 & 8 & $3 \%$ \\
indepentent physician & 5 & 2 & 7 & $2 \%$ \\
pharmacist & 7 & 0 & 7 & $2 \%$ \\
dentist, dental nurse & 4 & 2 & 6 & $2 \%$ \\
paramedic & 1 & 4 & 5 & $2 \%$ \\
midwife & 1 & 0 & 1 & $0 \%$ \\
other & 4 & 3 & 7 & $2 \%$ \\
\hline Total & 240 & 56 & 296 & $100 \%$ \\
\hline f=female, mamale, N=total & rel & relative percentage
\end{tabular}

$\mathrm{f}=$ female, $\mathrm{m}=$ male, $\mathrm{N}=$ total, rel=relative percentage

ranted. Importance of stress factors were estimated via (multiple) linear regressions after checking the test prerequisites. Odds ratio of seeking help was estimated by binary logistic regression. Our anonymized data set and codebook are available for download via the open science framework (OSF) website at: https://doi.org/ 10.17605/OSF . IO/EHM67 42

\section{Results}

\section{Stress Factors}

Participants reported that they were most affected by protective measures to avoid spreading of the virus as these impede both patient contact and work processes in general. The pandemic also led to various changes in work procedures. Table 3 provides an overview of the stress factors mentioned.

\section{Mental Health}

When analyzing the ISR scores, we first checked the internal consistency. The results were almost identical to previous findings with Cronbach's $\alpha$ ranging between $\alpha=0.78$ and $\alpha=0.9$ for the subscales and $\alpha=0.94$ for the total scale.

The observed severity of clinical symptoms was high on all scales (see Table 6 and Figure 1). In particular, the frequency of depression and anxiety symptoms was unexpectedly high, with $9 \%$ reporting severe depression symptoms and another $65 \%$ light to medium symptoms. A total of $41 \%$ reported at least light symptoms of anxiety while in reference group $R_{C-P-}$, assessed before the pandemic, only $21 \%$ displayed these levels of symptoms.

For all symptom scales, healthcare professionals scored significantly higher than the reference group $R_{C-P-}$ before the pandemic $(d f \geq 331.53, t \geq 5.36$, $p<.001$ ), but also lower than the clinical group $R_{C+P-}$ $(d f \geq 314.92, t \leq-9.08, p<.001)$. However, the increase cannot be explained by the lockdown measures alone. Healthcare professionals also showed significantly more symptoms than the general population reference group during the pandemic $\left(R_{C-P+}\right)$ on both the depression scale $(\Delta M=0.5,95 \%$ CI $[0.39,0.61], t(2072)=8.88$, $p<.001)$ and on the anxiety scale $(\Delta M=0.35,95 \% \mathrm{CI}$ $[0.23,0.47], t(383)=5.83, p<.001)$. Most notably, the rate of severe symptoms was significantly higher on both the depression scale $\left(\chi^{2}=1022.99, d f=1, p<.001\right)$ and the anxiety scale $\left(\chi^{2}=1024.29, d f=1, p<.001\right)$.

Which stress factors contributed to anxiety and depression? A multiple regression of the ISR depression score on the eight stress factors $\left(R^{2}=0.211, F(8,284)=\right.$ $9.47, p<.001)$ revealed that job insecurity was the single most important predictor of depression symptoms (see Table 4. While on average, participants felt that job insecurity hardly affected them $(M=1.15, S D=1.24$ on scale from 0 to 4 ), high levels of job insecurity were strongly associated with psychological symptoms. Anxiety about infection of family members and protective measures that hinder work processes were also good predictors of the level of depression symptoms. A second regression of the ISR anxiety score $\left(R^{2}=0.16\right.$, $F(8,284)=6.75, p<.001)$ showed a similar picture. Again, job insecurity and infection of family members were associated with anxiety symptoms. An increasing number of serious illnesses and deaths also contributed to anxiety (see Table 5).

Professionals with direct contact to patients $(M=$ 0.86 ) did not report more severe symptoms than those in administration (as categorized based on profession, $M=$ $1.03, t(50.1)=1.36, p=.91,1-\beta(d=0.5)=0.91)$. However, as people with pre-existing medical conditions are at higher risk, those with a condition were significantly more worried $\left(M_{\text {yes }}=1.13, M_{n o}=0.75, t(253.5)=3.36\right.$, $p<.001)$ and reported more severe symptoms overall $\left(M_{\text {yes }}=1.04, M_{n o}=0.76, t(260.2)=3.88, p<.001\right)$.

\section{Help Seeking}

Overall, the majority of participants described themselves as experiencing symptoms of depression and anxiety. Meanwhile, when asked whether they would like to receive psychological support to deal with the crisis, 


\section{Figure 1}

Comparison of the relative frequency of severity levels for the ISR scales. Error bars indicate 95\% confidence interval of the respective proportion.
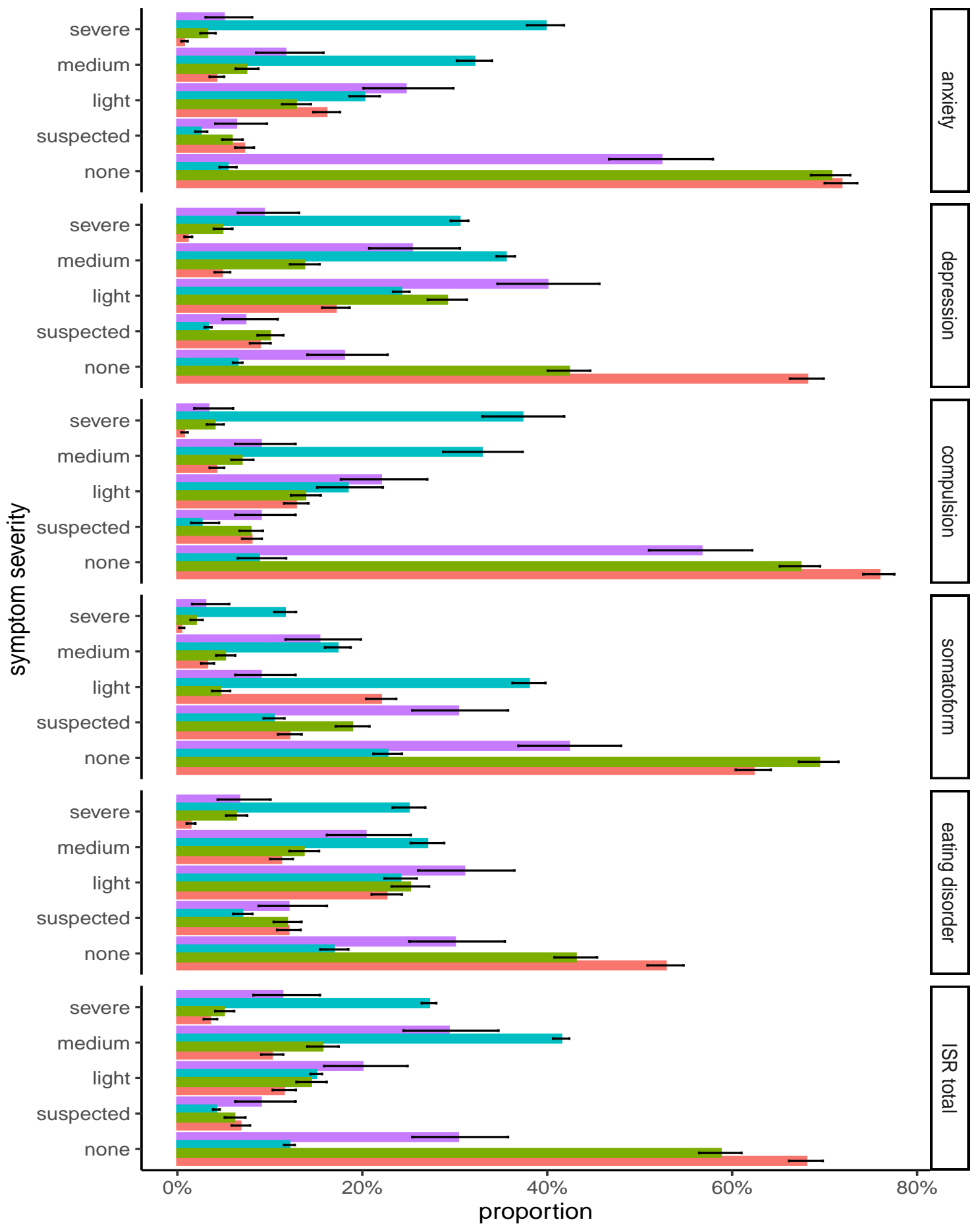

group $\quad$ C-P- $\quad \mathrm{C}-\mathrm{P}+_{-} \quad \mathrm{C}_{+} \mathrm{P}_{-} \quad$ healthcare professionals 
Table 3

How strongly are you affected by the following aspect during the COVID-19 pandemic at your work place? ( $0=$ not at all; $4=$ extremly)

\begin{tabular}{lccc}
\hline stress factor & $\mathrm{N}$ & $\mathrm{M}$ & $\mathrm{SD}$ \\
\hline protective measures hinder patient contact & 285 & 2.76 & 1.03 \\
protective measures hinder work processes & 297 & 2.58 & 1.00 \\
changes in work procedures & 298 & 2.57 & 1.04 \\
need for childcare in own household $^{\mathrm{a}}$ & 91 & 2.36 & 1.51 \\
anxiety about infection of family members & 290 & 2.30 & 1.25 \\
limited contact to colleagues & 287 & 2.18 & 1.13 \\
anxiety about self-infection & 285 & 1.78 & 1.18 \\
increasing number of serious illnesses and deaths & 243 & 1.29 & 1.18 \\
job insecurity & 234 & 1.16 & 1.25 \\
\hline
\end{tabular}

$\mathrm{N}=$ total, $\mathrm{M}=$ mean, $\mathrm{SD}=$ std. deviation

athis item was presented conditional on response to previous question about having children; number of children not assessed.

Table 4

Multiple regression of ISR depression score on stress factors

\begin{tabular}{lcccl}
\hline Predictor & $b$ & $95 \%$ CI & $t(284)$ & $p$ \\
\hline Intercept & 0.45 & {$[0.12,0.78]$} & 2.67 & .008 \\
changes in work procedures & 0.03 & {$[-0.07,0.13]$} & 0.61 & .542 \\
protective measures hinder work processes & 0.12 & {$[0.01,0.23]$} & 2.23 & $.026^{*}$ \\
protective measures hinder patient contact & 0.07 & {$[-0.02,0.16]$} & 1.56 & .119 \\
limited contact to colleagues & -0.01 & {$[-0.10,0.07]$} & -0.31 & .759 \\
anxiety about self-infection & 0.04 & {$[-0.06,0.13]$} & 0.73 & .465 \\
anxiety about infection of family members & 0.15 & {$[0.05,0.24]$} & 3.03 & $.003^{* *}$ \\
job insecurity & 0.16 & {$[0.07,0.24]$} & 3.73 & $<.001^{* * *}$ \\
increasing number of serious illnesses and deaths & 0.03 & {$[-0.05,0.11]$} & 0.67 & .506 \\
\hline
\end{tabular}

Note. $\mathrm{b}=$ unstandardized regression coefficient; $\mathrm{CI}=$ confidence interval; ${ }^{*} p<.05,{ }^{* *} p<.01$, ${ }^{* * *} p<.001, R^{2}=0.211$, adjusted $R^{2}=0.188, F(8,284)=9.47, p<.001$

most participants declined (see Table 7). Out of the 300 participants, $209(70 \%)$, scored 0.5 or higher on the ISR total scale which is considered suspected clinical diagnosis or more severe. However, only $84(40 \%)$ of these said that they would consider seeking psychological help. A binary logistic regression revealed that the higher the ISR score the more likely participants were to seek help $(b=1.61, O R=5.01, z=6.54, p<.001)$.

Why are those who supposedly need help not seeking help? 100 (48\%) of the 209 participants who are supposedly in need claimed that others would need the support more urgently. $70(33 \%)$ were not aware of suitable support services or offers. $66(32 \%)$ felt that they were not distressed enough to require support. And 52
(25\%) claimed that they did not have time for seeking help. The majority - with $82 \%$ of all participants and $79 \%$ of those who supposedly need help-indicated to have sufficient social support outside the work place.

\section{Discussion}

Consistent with reports from other countries and with our expectations, healthcare professionals in Germany report high levels of depression and anxiety during the pandemic. Severe levels of depression symptoms were reported by $9.3 \%$ and severe symptoms of anxiety by $5 \%$ of participants. These values were consistently above those reported by a general population sample during the pandemic and below a clinical sample prior to the 
Table 5

Multiple regression of ISR anxiety score on stress factors

\begin{tabular}{lcccl}
\hline Predictor & $b$ & $95 \%$ CI & $t(284)$ & $p$ \\
\hline Intercept & 0.19 & {$[-0.18,0.55]$} & 1.00 & .316 \\
changes in work procedures & -0.01 & {$[-0.12,0.10]$} & -0.17 & .868 \\
protective measures hinder work processes & 0.03 & {$[-0.09,0.15]$} & 0.45 & .653 \\
protective measures hinder patient contact & -0.01 & {$[-0.11,0.09]$} & -0.11 & .910 \\
limited contact to colleagues & 0.03 & {$[-0.07,0.12]$} & 0.60 & .546 \\
anxiety about self-infection & -0.02 & {$[-0.12,0.09]$} & -0.32 & .751 \\
anxiety about infection of family members & 0.19 & {$[0.08,0.30]$} & 3.55 & $<.001^{* * *}$ \\
job insecurity & 0.13 & {$[0.04,0.23]$} & 2.91 & $.004^{* *}$ \\
increasing number of serious illnesses and deaths & 0.12 & {$[0.03,0.21]$} & 2.51 & $.012^{*}$ \\
\hline
\end{tabular}

Note. $\mathrm{b}=$ unstandardized regression coefficient; $\mathrm{CI}=$ confidence interval; ${ }^{*} p<.05,{ }^{* *} p<.01$, ${ }^{* * *} p<.001, R^{2}=0.16$, adjusted $R^{2}=0.136, F(8,284)=6.75, p<.001$

\section{Table 6}

Severity of symptoms in ISR in comparison to the three reference groups.

\begin{tabular}{llccccc}
\hline scale & group & none & suspected & light & medium & severe \\
\hline anxiety & healthcare professionals & $52.3 \%$ & $6.3 \%$ & $24.7 \%$ & $11.7 \%$ & $5 \%$ \\
& $\mathrm{C}+\mathrm{P}-$ & $5.4 \%$ & $2.5 \%$ & $20.2 \%$ & $32.1 \%$ & $39.8 \%$ \\
& $\mathrm{C}-\mathrm{P}+$ & $70.7 \%$ & $5.9 \%$ & $12.8 \%$ & $7.4 \%$ & $3.2 \%$ \\
& $\mathrm{C}-\mathrm{P}-$ & $71.8 \%$ & $7.2 \%$ & $16.1 \%$ & $4.2 \%$ & $0.7 \%$ \\
\hline \multirow{2}{*}{ depression } & healthcare professionals & $18 \%$ & $7.3 \%$ & $40 \%$ & $25.3 \%$ & $9.3 \%$ \\
& $\mathrm{C}+\mathrm{P}-$ & $6.5 \%$ & $3.3 \%$ & $24.2 \%$ & $35.5 \%$ & $30.5 \%$ \\
& $\mathrm{C}-\mathrm{P}+$ & $42.3 \%$ & $10 \%$ & $29.1 \%$ & $13.7 \%$ & $4.8 \%$ \\
& $\mathrm{C}-\mathrm{P}-$ & $68.1 \%$ & $8.9 \%$ & $17.1 \%$ & $4.8 \%$ & $1.1 \%$ \\
\hline \multirow{2}{*}{ compulsion } & healthcare professionals & $56.7 \%$ & $9 \%$ & $22 \%$ & $9 \%$ & $3.3 \%$ \\
& $\mathrm{C}+\mathrm{P}-$ & $8.8 \%$ & $2.6 \%$ & $18.4 \%$ & $32.9 \%$ & $37.3 \%$ \\
& $\mathrm{C}-\mathrm{P}+$ & $67.4 \%$ & $7.9 \%$ & $13.8 \%$ & $6.9 \%$ & $4 \%$ \\
& $\mathrm{C}-\mathrm{P}-$ & $75.9 \%$ & $8 \%$ & $12.8 \%$ & $4.2 \%$ & $0.7 \%$ \\
\hline \multirow{2}{*}{ somatoform } & healthcare professionals & $42.3 \%$ & $30.3 \%$ & $9 \%$ & $15.3 \%$ & $3 \%$ \\
& $\mathrm{C}+\mathrm{P}-$ & $22.7 \%$ & $10.4 \%$ & $38 \%$ & $17.3 \%$ & $11.6 \%$ \\
& $\mathrm{C}-\mathrm{P}+$ & $69.4 \%$ & $18.9 \%$ & $4.6 \%$ & $5.1 \%$ & $2 \%$ \\
& $\mathrm{C}-\mathrm{P}-$ & $62.3 \%$ & $12.1 \%$ & $22 \%$ & $3.2 \%$ & $0.4 \%$ \\
\hline \multirow{5}{*}{ eating disorder } & healthcare professionals & $30 \%$ & $12 \%$ & $31 \%$ & $20.3 \%$ & $6.7 \%$ \\
& $\mathrm{C}+\mathrm{P}-$ & $16.9 \%$ & $7 \%$ & $24.1 \%$ & $27 \%$ & $25 \%$ \\
& $\mathrm{C}-\mathrm{P}+$ & $43.1 \%$ & $11.8 \%$ & $25.1 \%$ & $13.6 \%$ & $6.3 \%$ \\
& $\mathrm{C}-\mathrm{P}-$ & $52.8 \%$ & $12 \%$ & $22.6 \%$ & $11.2 \%$ & $1.4 \%$ \\
\hline \multirow{5}{*}{ ISR total } & healthcare professionals & $30.3 \%$ & $9 \%$ & $20 \%$ & $29.3 \%$ & $11.3 \%$ \\
& $\mathrm{C}+\mathrm{P}-$ & $12.1 \%$ & $4.2 \%$ & $15 \%$ & $41.5 \%$ & $27.2 \%$ \\
& $\mathrm{C}-\mathrm{P}+$ & $58.7 \%$ & $6.1 \%$ & $14.4 \%$ & $15.7 \%$ & $5 \%$ \\
& $\mathrm{C}-\mathrm{P}-$ & $68 \%$ & $6.8 \%$ & $11.5 \%$ & $10.2 \%$ & $3.5 \%$ \\
\hline
\end{tabular}




\section{Table 7}

Frequency of responses to 'Would you like to receive psychological support to deal with the crisis?' categorized by supposed need for support based on ISR scale.

\begin{tabular}{lccc}
\hline & \multicolumn{3}{c}{ in need } \\
\cline { 2 - 3 } Would you seek psychological help? & no & yes & total \\
\hline No, I am fine. & 53 & 35 & 88 \\
No, I get sufficient support. & 25 & 54 & 79 \\
No, I prefer to deal with it on my own. & 6 & 36 & 42 \\
I will consider it. & 7 & 60 & 67 \\
Yes, but not psychotherapy. & 0 & 14 & 14 \\
Yes, psychotherapy. & 0 & 10 & 10 \\
\hline All & 91 & 209 & 300 \\
\hline 'no' means $I S R<0.5$; 'yes' means $I S R \geq 0.5$ & & &
\end{tabular}

'no' means $I S R<0.5$; 'yes' means $I S R \geq 0.5$

pandemic; yet reported help-seeking intentions were low.

The reported severity of symptoms is in line with previous studies on the mental health effects of the COVID19 pandemic on medical staff from other countries [e.g., 7. 6], which, according to a review, place the prevalence of severe symptoms between $2.2 \%$ and $14.5 \%$. German healthcare workers' level of strain is even more elevated than that of the general population during the pandemic assessed a few weeks before our sample. This is particularly concerning. As the pandemic reached its first peak across the globe, even countries which had been under-funding and neglecting their healthcare systems were forcibly made aware of the crucial importance of healthcare workers. Politicians and members of the general public expressed their appreciation for system-relevant or essential workers - medical frontline staff representing a key group among them. In light of this, it seems crucial to take measures to reduce psychological strain on these workers - particularly because both the pandemic and the consequences of the psychological distress caused by it are expected to persist for the foreseeable future. Depression and fatigue are correlated with perceived medical errors. In a study with medicine trainees, the odds ratio associated with a positive depression screen was $O R=2.22$, i.e., those screened positively were much more likely to report an error 43 .

However, in spite of the severity of reported psychological strain, reported help-seeking behaviour and helpseeking intentions were consistently low. Many healthcare professionals are not seeking help, citing either concern for the distribution of resources (i.e., based on the assumption that a limited amount of psychological support is available, they stated that others needed it more than they did, they themselves were not distressed enough to require support, and/or they already had a sufficient support network) or accessibility issues (not having time to seek help, not being aware of a service that meets their needs).

This points to two underlying issues: Firstly, while several employers, public agencies and private non-profit organizations hurried to create mental health services to support healthcare staff during the pandemic, e.g., telephone hotlines like Talk2Us 29 and free-of-charge psychotherapy provided to nursing staff by the German professional association for nursing staff [44], it seems that these were overall not accessible enough or did not meet healthcare staff's perceived needs. One issue was, most likely, awareness; since most of these support services were set up at the beginning of the pandemic and had, therefore, only been active for a few months at the time we conducted our survey, they were not well-known and established among healthcare workers yet. This would explain why about one third of our sample claimed not to be aware of a suitable service. Just over a quarter of participants stated they did not have time to seek help, which might indicate that current service offers do not fit with demand. Future research should investigate how support services should be designed to meet healthcare staff's needs, e.g., by being flexible to suit the staff's schedules, being less time-consuming than current services are perceived to be and being more easily accessible.

Secondly, the large portions of our sample claiming that they were not in need of support in spite of the severely elevated levels of mental strain, that they already had sufficient support and that others needed it more urgently seem to be indicative of a climate that discourages help-seeking behaviour and speaking out about mental health issues in the healthcare community. A work culture pervaded by the general expectation to 
prioritize patient care before personal well-being and to refrain from acts that could be interpreted as displaying weakness, such as admitting to being overwhelmed or seeking professional help [45], could be a crucial factor inhibiting help-seeking behaviour.

It is crucial that future research also investigates the work-climate and culture in the healthcare sector and the norms it sets around mental health; explorative qualitative studies seem warranted. While social norms of this kind are complex and slow to change, it is crucial they be identified and addressed, because if stigmatization of help-seeking behaviour truly is prevalent in the healthcare community, improving the accessibility of support services alone is bound to have very limited effects on the rates of healthcare workers seeking help. What our data, alongside various other studies, have done is establish that there is a need to provide mental health support to the healthcare community; the question that research must target next is why and when this need does and does not translate to a demand.

\section{References}

1. Cox CL. Healthcare Heroes: problems with media focus on heroism from healthcare workers during the COVID-19 pandemic. Journal of Medical Ethics 2020; 46:510-3. DOI: 10.1136/medethics2020-106398

2. Zacher $\mathrm{H}$ and Rudolph CW. Individual differences and changes in subjective wellbeing during the early stages of the COVID-19 pandemic. American Psychologist 2020. DOI: 10.1037/amp0000702

3. Krammer S, Augstburger R, Haeck M, and Maercker A. Adjustment disorder, depression, stress symptoms, Corona related anxieties and coping strategies during the Corona pandemic (COVID19) in Swiss medical staff. PPmP-Psychotherapie - Psychosomatik - Medizinische Psychologie 2020 Jul; 70:272-82. DOI: 10.1055/a-1192-6608

4. Du J, Dong L, Wang T, Yuan C, Fu R, Zhang L, Liu B, Zhang M, Yin Y, Qin J, Bouey J, Zhao M, and Li X. Psychological symptoms among frontline healthcare workers during COVID-19 outbreak in Wuhan. General Hospital Psychiatry 2020. DOI: 10.1016/j.genhosppsych.2020.03.011

5. Lu W, Wang H, Lin Y, and Li L. Psychological status of medical workforce during the COVID-19 pandemic: A cross-sectional study. Psychiatry Research 2020 Jun; 288:112936. DOI: 10.1016/j. psychres.2020.112936
6. Liu CY, Yang YZ, Zhang XM, Xu X, Dou QL, Zhang WW, and Cheng ASK. The prevalence and influencing factors in anxiety in medical workers fighting COVID-19 in China: a cross-sectional survey. Epidemiology \& Infection 2020 May; 148:e98. DOI: $10.1017 / \mathrm{S} 0950268820001107$

7. Kang L, Ma S, Chen M, Yang J, Wang Y, Li R, Yao L, Bai H, Cai Z, Xiang Yang B, Hu S, Zhang $\mathrm{K}$, Wang G, Ma C, and Liu Z. Impact on mental health and perceptions of psychological care among medical and nursing staff in Wuhan during the 2019 novel coronavirus disease outbreak: A cross-sectional study. Brain, Behavior, and Immunity 2020 Jul; 87:11-7. DOI: $10.1016 / \mathrm{j} . \mathrm{bbi}$. 2020.03 .028

8. Bohlken J, Schömig F, Lemke MR, Pumberger M, and Riedel-Heller SG. COVID-19 pandemic: stress experience of healthcare workers - a short current review. Psychiatrische Praxis 2020 May; 47:190-7. DOI: $10.1055 / \mathrm{a}-1159-5551$

9. Lai J, Ma S, Wang Y, Cai Z, Hu J, Wei N, Wu J, Du H, Chen T, Li R, Tan H, Kang L, Yao L, Huang M, Wang H, Wang G, Liu Z, and $\mathrm{Hu}$ S. Factors associated with mental health outcomes among health care workers exposed to Coronavirus Disease 2019. JAMA Network Open 2020 Mar; 3:e203976. DOI: 10.1001/jamanetworkopen.2020.3976

10. Makino M, Kanie A, Nakajima A, and Takebayashi Y. Mental health crisis of Japanese health care workers under COVID-19. Psychological Trauma: Theory, Research, Practice, and Policy 2020; 12:S136-S137. DoI: 10.1037/tra0000819

11. Barello S, Palamenghi L, and Graffigna G. Burnout and somatic symptoms among frontline healthcare professionals at the peak of the Italian COVID19 pandemic. Psychiatry Research 2020 :113129. DOI: $10.1016 / \mathrm{j} \cdot$ psychres.2020.113129

12. Temsah MH, Al-Sohime F, Alamro N, Al-Eyadhy A, Al-Hasan K, Jamal A, Al-Maglouth I, Aljamaan F, Al Amri M, Barry M, Al-Subaie S, and Somily AM. The psychological impact of COVID-19 pandemic on health care workers in a MERS-CoV endemic country. Journal of Infection and Public Health 2020 Jun; 13:877-82. DOI: $10.1016 / j$. jiph.2020.05.021

13. Miller K. Mental and emotional risks of frontline healthcare providers involved in responding to COVID-19 Pandemic. Psychosociological Issues in Human Resource Management 2020; 8:19-24. DOI: 10.22381/PIHRM8120203 
14. El-Hage W, Hingray C, Lemogne C, Yrondi A, Brunault P, Bienvenu T, Etain B, Paquet C, Gohier B, Bennabi D, Birmes P, Sauvaget A, Fakra E, Prieto N, Bulteau S, Vidailhet P, Camus V, Leboyer M, Krebs MO, and Aouizerate B. Health professionals facing the coronavirus disease 2019 (COVID-19) pandemic: What are the mental health risks? L'Encephale 2020 Jun; 46:S73-S80. DOI: $10.1016 / \mathrm{j}$.encep. 2020.04 .008

15. Preti E, Di Mattei V, Perego G, Ferrari F, Mazzetti M, Taranto P, Di Pierro R, Madeddu F, and Calati R. The psychological impact of epidemic and pandemic outbreaks on healthcare workers: rapid review of the evidence. Current Psychiatry Reports 2020 Jul; 22:43. DOI: 10 . 1007 / s11920-02001166-z

16. Hall H. The effect of the COVID-19 pandemic on healthcare workers' mental health. Journal of the American Academy of Physician Assistants 2020 Jul; 33:45-8. DOI: 10.1097/01 . JAA . 0000669772 . $78848.8 \mathrm{c}$

17. Shanafelt T, Ripp J, and Trockel M. Understanding and addressing sources of anxiety among health care professionals during the COVID-19 pandemic. Journal of the American Medical Association 2020; 323:2133-4. DOI: $10.1001 /$ jama. 2020.5893

18. Chen Q, Liang M, Li Y, Guo J, Fei D, Wang L, He L, Sheng C, Cai Y, Li X, Wang J, and Zhang Z. Mental health care for medical staff in China during the COVID-19 outbreak. The Lancet Psychiatry 2020; 7:e15-e16. DOI: $10.1016 /$ S22150366 (20) 30078-X

19. Satici B, Saricali M, Satici SA, and Griffiths MD. Intolerance of uncertainty and mental wellbeing: serial mediation by rumination and fear of COVID19. International Journal of Mental Health and Addiction 2020. DOI: $10.1007 / \mathrm{s} 11469-020-00305-0$

20. Xiao H, Zhang Y, Kong D, Li S, and Yang N. The effects of social support on sleep quality of medical staff treating patients with coronavirus disease 2019 (COVID-19) in January and February 2020 in China. Medical Science Monitor: International Medical Journal of Experimental and Clinical Research 2020; 26:e923549-1. DOI: 10.12659/MSM . 923549

21. Jex SM and Bliese PD. Efficacy beliefs as a moderator of the impact of work-related stressors: a multilevel study. Journal of Applied Psychology 1999; 84:349. DOI: $10.1037 / 0021-9010.84 .3 .349$
22. Champion VL and Skinner CS. The Health Belief Model. Health Behavior and Health Education: Theory, Research, and Practice. Ed. by Glanz K, Rimer BK, and Viswanath K. 4th ed. 2008 :45-65

23. Ho SM, Kwong-Lo RS, Mak CW, and Wong JS. Fear of severe acute respiratory syndrome (SARS) among health care workers. Journal of Consulting and Clinical Psychology 2005; 73:344. DOI: 10 . 1037/0022-006X.73.2.344

24. Miotto K, Sanford J, Brymer MJ, Bursch B, and Pynoos RS. Implementing an emotional support and mental health response plan for healthcare workers during the COVID-19 pandemic. Psychological Trauma: Theory, Research, Practice, and Policy 2020; 12:S165-S167. DOI: $10.1037 /$ tra0000918

25. Greenberg N, Docherty M, Gnanapragasam S, and Wessely S. Managing mental health challenges faced by healthcare workers during COVID-19 pandemic. BMJ 2020; 368. DOI: $10.1136 / \mathrm{bmj}$. m1211

26. Blake H, Bermingham F, Johnson G, and Tabner A. Mitigating the psychological impact of COVID19 on healthcare workers: a digital learning package. International Journal of Environmental Research and Public Health 2020 Apr; 17. DOI: 10 . 3390/ijerph17092997

27. Feinstein RE, Kotara S, Jones B, Shanor D, and Nemeroff CB. A health care workers mental health crisis line in the age of COVID-19. Depression and Anxiety 2020. DOI: $10.1002 /$ da. 23073

28. Gonzalez A, Cervoni C, Lochner M, Marangio J, Stanley C, and Marriott S. Supporting health care workers during the COVID-19 pandemic: Mental health support initiatives and lessons learned from an academic medical center. Psychological Trauma: Theory, Research, Practice, and Policy 2020; 12:S168-S170. DOI: 10.1037/tra0000893

29. Reiter J and Duden G. Talk2Us website. 2020. Available from: https://www.talk2us.de/ [Accessed on: 2020 Oct 11]

30. Cohen J and Kupferschmidt K. Countries test tactics in 'war' against COVID-19. Science 2020; 367(6484):1287-8

31. Torri E, Sbrogiò LG, Di Rosa E, Cinquetti S, Francia F, and Ferro A. Italian Public Health Response to the COVID-19 Pandemic: Case Report from the Field, Insights and Challenges for the Department of Prevention. International Journal of Environmental Research and Public Health 2020; 17:3666. DOI: $10.3390 /$ ijerph17103666 
32. Tritt K, Heymann F von, Zaudig M, Zacharias I, Söllner W, and Loew T. Development of the ICD-10-Symptom-Rating (ISR) questionnaire. Zeitschrift für Psychosomatische Medizin und Psychotherapie 2008; 54:409-18. DOI: $10.13109 /$ zptm.2008.54.4.409

33. World Health Organization. ICD-10: International statistical classification of diseases and related health problems. Vol. 1. World Health Organization, 2004

34. Fischer HF, Tritt K, Klapp BF, and Fliege H. Factor Structure and Psychometric Properties of the ICD-10-Symptom-Rating (ISR) in Samples of Psychosomatic Patients. PPmP-Psychotherapie • Psychosomatik - Medizinische Psychologie 2010; 60:307-15. DOI: $10.1055 / \mathrm{s}-0029-1214419$

35. Fischer HF, Schirmer N, Tritt K, Klapp BF, and Fliege H. Retest-reliability and sensitivity to change of the ICD-10-Symptom-Rating (ISR) in different samples. PPmP-Psychotherapie - Psychosomatik - Medizinische Psychologie 2010; 61:1629. DOI: $10.1055 / \mathrm{s}-0030-1249683$

36. Tritt K, Heymann F von, Zaudig M, Probst T, Loew T, Klapp B, Söllner W, Fydrich T, and Bühner M. ICD-10-Symptom-Rating (ISR) - Das Handbuch zum Fragebogen. neobooks, 2015

37. Schmitz N, Hartkamp N, Kiuse J, Franke G, Reister G, and Tress W. The Symptom Check-List-90R (SCL-90-R): a German validation study. Quality of Life Research 2000; 9:185-93

38. Tritt K, Heymann F von, Zaudig M, Söllner W, Klapp B, Loew T, and Bühner M. Der Fragebogen ICD-10-Symptom-Rating (ISR) - Kurzdarstellung der Normierung. 2010. Available from: http : / / www . iqp-online . de/index . php? page= download
39. Schelhorn I, Ecker A, Bereznai J, Tran T, Rehm S, Lugo R, Sütterlin S, Kinateder M, and Shiban Y. Depression symptoms during the COVID-19 pandemic in different regions in Germany. 2020 Jul. DOI: 10.31234 / osf . io/p9wz8. Available from: psyarxiv.com/p9wz8

40. R Core Team. R: A Language and Environment for Statistical Computing. R Foundation for Statistical Computing. Vienna, Austria, 2020. Available from: https://www.R-project.org/

41. RStudio Team. RStudio: Integrated Development Environment for R. RStudio, PBC. Boston, MA, 2020. Available from: http://www.rstudio.com/

42. Weibelzahl S, Duden G, and Reiter J. PandemicInduced psychological stress in healthcare professionals. 2020 Oct. DOI: 10.17605/OSF. IO/EHM67 Available from: osf.io/ehm67

43. West CP, Tan AD, Habermann TM, Sloan JA, and Shanafelt TD. Association of Resident Fatigue and Distress With Perceived Medical Errors. JAMA 2009 Sep; 302:1294-300. DOI: 10 . $1001 /$ jama . 2009 . 1389. eprint: https : / / jamanetwork.com/ journals / jama/articlepdf / 184625/joc90102\ _1294\_1300.pdf. Available from: https://doi. org/10.1001/jama.2009.1389

44. Deutscher Berufsverband für Pflegeberufe [German professional association for nursing staff]. Psych4Nurses website. 2020. Available from: https : / / www . dbfk . de / de / themen / psych4nurses.php [Accessed on: 2020 Oct 11]

45. Galbraith ND, Brown KE, and Clifton E. A survey of student nurses' attitudes toward help seeking for stress. Nursing Forum 2014; 49:171-81. DOI: $10.1111 /$ nuf .12066 